Piotr Kazimierowski

AUDIT RAIL Sp. z o.o.

biuro@ auditrail.pl

\title{
Requirements for rail service
}

\begin{abstract}
One of the elements of the integration process of the European Union is striving to remove barriers to the free movement of persons, goods, services and capital between the countries of the Community. This process does not bypass means that rail transport for environmental reasons is promoted, developed and is to constitute one of the pillars of building cohesion, despite the numerous technological diff erences existing between the systems in the individual EU countries. These measures are aimed as soon as possible to ensure interoperability between countries and transport systems.
\end{abstract}

Keywords: Railway infrastructure; Transport demands

\section{What we forget}

One of the elements of the European Union integration process is striving to remove barriers to the free movement of persons, goods, services and capital between the countries of the Community. This process does not avoid rail transport which for environmental reasons is promoted, developed and is intended to be one of the pillars of building cohesion, despite the numerous technological differences existing between the systems in the individual EU countries. These measures are aimed as soon as possible to ensure interoperability between countries and transport systems.

As it turns out in the design and implementation of major rail infrastructure investment we often forget about creating objects of the technical infrastructure necessary for proper and safe operation, in full rail network interpretation such as:

- appropriate length and height of the platforms, compatible with the strategy of public transport organizers and rolling stock investments,

- additional stabling tracks for passenger and cargo trains,

- public technical facilities, including cleaning and washing facilities,

- public railway stations and installations for refueling,

- tracks and installations for heating the passenger trains,

- tracks allowing inspections and technical revision of rolling stock,

- tracks for emergency leave off carriages carrying dangerous goods,

- adjust the traction network and substations to operate high-power locomotives, including the double traction.

The lack of solutions and arising problems connected with this issue has already been some time ago noticed by the countries of the Community and solved in a systematic way by including it in the EU legislation.

\section{Legal environment}

Due to the fact that not all of these issues are contained in a clear, precise way and described in detail in the Directives and Regulations, it is the role of the scientific, engineering environment is listening to the needs of the market and predicting for many years into the future demand for services related to the use of the railway infrastructure. That is why so much depends on the quality and reliability of the executed feasibility studies, simulations and 
modernization plans that advantage which is a very long life infrastructure projects did not become a curse and a hindrance to the development of railways in Poland.

The basic legal act that changes in a fundamental way looking at the process of railway investments, and in particular their scope is Directive of the European Parliament and Council Directive 2012/34 / EU of 21 November 2012 establishing a single European railway area. This act integrates into a single document, and replaces the existing documents that form the basis of the single rail transport system in Europe that formed the Council Directive 91/440 / EEC of 29 July 1991 on the development of the Community, Council Directive 95/18 / EC of 19 June 1995 on the licensing of railway undertakings and Directive 2001/14 / EC of the European Parliament and of the Council of 26 February 2001 on the allocation of railway infrastructure capacity and the levying of charges for the use of railway infrastructure.

This document very clearly highlights the need for existing and sharing under not discriminated principles not only railways but also the service infrastructure, which is an integral part of an efficient, interpretive railway system. The significance and importance of infrastructure services for the viability of an open rail market provide up to 3 paragraphs that directly relate to these issues:

- point (12) „Due to the fact that the private branch lines and sidings, branching from the station and wayside tracks, such as sidings and works lines, are not part of the railway infrastructure as defined by this Directive, managers of such infrastructures should not be subject to the obligations imposed on infrastructure managers under this Directive. However, to ensure non-discriminatory access to branch lines and sidings, regardless of their ownership, when the track access roads to service facilities that are necessary for the provision of transport services and when they serve or can serve more than one end customer",

- point (26) „In order to ensure fair competition between railway undertakings and guarantee full transparency and non-discriminatory access to services and their provision distinction should be made between the provision of transport services and the operation of service facilities. In this connection it is necessary for these two activities to be managed independently in the event that the operator of the service facility belongs to a body or firm which is also active and holds a dominant position at national level in at least one of the railway transport markets in relation for the carriage of goods or passengers, for which the object is used. Such independence should not entail the establishment of a separate legal entity for service facilities",

- point (27), Non-discriminatory access to service facilities and the provision of services related to the sector turn in these facilities should allow railway undertakings to improve the quality of services provided to passengers and freight users".

The term of the service facility should be understood as installation, including ground, building and equipment, which have been specially prepared in whole or in part, to allow the provision of one or more of the services referred to Annex II of the Directive 2-4. As the operator of the service facility shall be determined any public or private entity responsible for managing one or more service facilities or railway undertakings providing one or more services referred to Annex II 2-4.

As indicated by the content of point 2 of Annex II, as the service facilities is defined, among others,:

- passenger stations, their buildings and other facilities, including information display for passengers and convenient ticketing,

- freight terminals,

- marshalling yards and equipment for the formation of trains, including maneuvering device, 
- stabling tracks,

- points of technical hinterland, with the exception of points corrective maintenance designed for high-speed trains or other types of rolling stock requiring specialistic hinterland,

- other technical facilities, including cleaning and washing facilities,

- maritime and inland port infrastructure with access to the tracks,

- auxiliary installations,

- railway stations and installations for refueling, for which charges are on the invoices separately.

Point 3 mentioned Annex sets out additional services, which may include:

- traction current, for which charges are shown on the invoices separately from charges for using the electrical supply, without prejudice to the application of Directive 2009/72 / EC,

- heating of passenger trains,

- contracts tailored to individual customer needs on:

○ control over transport of dangerous goods,

$\circ$ assistance in running special trains.

However, in the point 4 are listed examples of auxiliary services which may include:

- access to telecommunications networks,

- providing supplementary information,

- technical inspection of rolling stock,

- ticket sales in passenger stations,

- repair maintenance of rolling stock provided in paragraphs of echnical hinterland designed for high-speed trains or other types of rolling stock requiring specialist facilities.

As you can see range of additional services and support that should be offered to carriers based on the service infrastructure is very wide and covers virtually all steps necessary to properly and safely support the implementation process of the railway passenger and freight.

Unfortunately, in the process of planning railway investments in Poland almost completely forgotten about this type of infrastructure. Perhaps this is intentional and calculated the effect of short-term support of the largest domestic carriers, but in the long term, by reducing interoperability can contribute to a loss of competitiveness against other modes of transport.

Gradual implementation of the requirements of the directive into national law of the EU and, especially in the technical specifications for interoperability and the new regulations will force countries to standardization of transport systems and complement the existing network of the missing infrastructure. For this reason, today, preparing to absorb the new EU funds and the subsequent modernization worth briefly bring infrastructure managers, designers and contractors on these aspects that should be noted in the context of the legal requirements and the needs of operators and rail and include them in their projects.

\section{Platforms and their height}

Examinations conducted in recent years among organisers of the public rail transport of the provincial rung irrefutably showed that in the past years the investment process carried out through the PLK Polish State Railways, in the train infrastructure associated with the service of passenger transports, practically in no way had been consulted. It is all more surprising in order not to say outrageous, that because of the lack of consultation between the infrastructure manager and the organiser of the transport, they made sequence of the modernization, 
including particularly heights of platforms which were in no way adapted to requirements of regulation (EC) No. 1371 / 2007 concerning the European Parliament and Advice of rights and obligations of passengers in the rail traffic in range of persons with restricted physical abilities.

Also cases of the modernization of platforms happened on railway lines on which the organiser in coming years isn't going to conduct passenger transports. What's more in the process of selection of the height of platforms, including in the vicinity of big urbanized areas a height was applied $0.55 \mathrm{~m}$ if as part of the agglomerative movement it is necessary to apply the height $0.76 \mathrm{~m}$, but dominating rolling stock on these lines EN57 series which probably will be used there for decadeshas a height of accessing at the level 1.1-1.2 m. Most often in order of apparent savings contractor with the consent of the infrastructure managers without any consultation with the organizer of public transport and carrier, used the height of the platforms only $0.55 \mathrm{~m}$ instead of $0.76 \mathrm{~m}$.

Fortunately indirect provision on the need for consultation with the organizer of public transport and carrier introduced the Regulation of the Minister of Infrastructure and Development of June 5, 2014. amending regulation on technical conditions to be met by railway structures and their location. According to this document, art. 98 paragraph. 8 received new sound "The height of the platform should be $0.76 \mathrm{~m}$ or $0.55 \mathrm{~m}$ above the rail head, depending on the type of railway vehicle stopping at the platform."

As you can see the original and recommended height of the platform is $0.76 \mathrm{~m}$, and the decision to use a different amount must result not from the investors' or manager of infrastructure "whim", but from the type of rolling stock which has to stop at the platform. About which camp stops there is determined primarily by the organizer of public transport, or marshal of the province, the minister responsible for transport or the mayor, if we talk about urban railways stops.

For these reasons, it is necessary the occurrence of by drawing up entities appropriate design documentation and analysis for the modernization of platforms in written form either to the competent territorial public transport operators and carriers operating there. In case of modernization of large stations a good practice would be applying to all operators on the Polish market for carriers, because you must take into account the possibility of implementing their transport outside the area of its operation, as is for example. In the case of a holiday train "Słoneczny" Mazovian Railways, which for years connects Pomerania with the capital.

It seems appropriate to introduce into the canon of good investment practices iron rule that the modernization of all platforms at the basic railway network on electrified lines to perform a height of $0.76 \mathrm{~m}$ and platforms at stations and stops non-electrified lines at the level of 0.55 $\mathrm{m}$. Of course, except for the Warsaw Node and Tri-City, due to the historical roots of these networks and already made investments. The adoption of such a practice would allow for the gradual introduction of standardization of the railway network and simplify the process of adaptation of rolling stock.

In addition the height of the platforms should also verify unsuitable to the current conditions of the guidelines in terms of their length, especially in terms of local lines and urban railways. Fortunately, here comes with help Regulation of Commission (EU) No 1299/2014 of 18 November 2014 concerning the technical specifications for interoperability relating to the 'infrastructure' rail system in the European Union, which defines the length of the utility platforms, depending on the operating parameters and the type of traffic. Thanks to movement of the P5 code and the maximum speed of $80-120 \mathrm{~km} / \mathrm{k}$, so the most popular parameters on local and agglomeration lines, there is a possibility of building platforms with a useful length of 50 to $200 \mathrm{~m}$.

Using these requirements, platforms should be built and modernized with a length of 50$60 \mathrm{~m}$ for small stops on the non-electrified lines corresponding to the length of dyadic railcar 
with supply. In contrast, platforms with a length of 150-160 m on electrified lines, allowing the freely to stop 3 and 4 elemented vehicles carried out even in a double traction (e.g. near agglomeration). For platforms of railway stations located at distances electrified lines optimum length of the platform should be $100 \mathrm{~m}$, to enable to stop 3 and 4 elemented vehicles in a single traction.

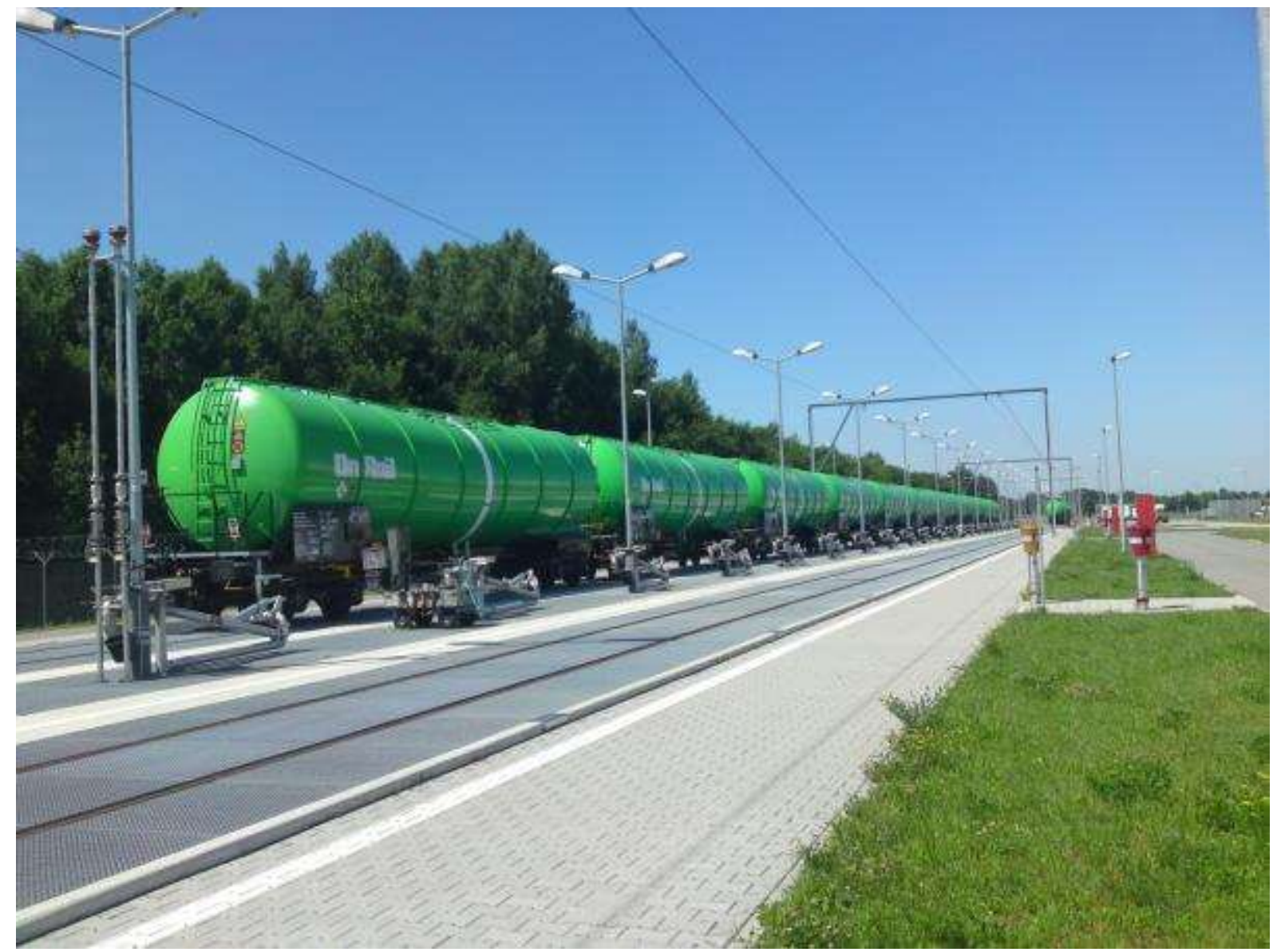

1. An example of a modern front to the handling of hazardous materials made of prefabricated elements non-ballasted railway track plates GTW type (Pic. BFL Lauchhammer)

\section{Cleaning and disposal of feaces}

With the introduction of the use of modern rolling stock, ubiquitous and very hygienic open systems toilets are things of the past. Although this process will probably take a few more years, it will disappear from the past toilets with proverbial "hole" that today there are very serious problems in this area. Accepted and used model of toilets with closed circuit requires systematic emptying tanks, as well as launching their vacuum flushing. Used in many cases by subcontractors current carriers pumping systems cause silting of reservoirs and gradually reducing their efficiency, which leads to more rapid overfilling the tank. As a result, in every modern passenger vehicle there must be disposal of feaces every day, and the water tank washed with aqueous reverse, while the clean water tank refilled, regardless of weather conditions, including even at very low temperatures.

While the systems toilets are equipped with systems to maintain a positive temperature even at very low temperatures, remains of water supply system that exist in the area of the railway are not. Only a few exceptions are the stations equipped with launching points at subzero temperatures. 
Different problem is open and equal to all market participants access to the point where it is possible in accordance with the requirements of environmental protection emptying tanks and launching vehicles. Today, virtually on a network of PKP PLK there is not a single point that meets both the requirements of environmental protection and the needs of carriers in terms of equipment and infrastructure to adapt to the needs of disposal of feaces in rail vehicles. In many of the existing points, disposal of feaces is carried out by "primitive" methods. These objects do not have a water permit and are not equipped with a special bathtub collecting leaks arising in the process of emptying the toilet to prevent their penetration into the ground and groundwater. Moreover, there is a lack of appropriate platforms, platforms and paved surfaces around the points, which would allow execution of operational activities at the camp in a safe manner and in accordance with the requirements of the safety management system of any railway carrier and infrastructure manager.

There is also no free access for cesspit emptiers or place for setting disposal of feaces fixed points. It all makes that rail operators have increasing and totally unjustified costs, leaving vehicles at their bases, passing sometimes unproductive tens of kilometers a day just because of the need to perform activities in the field of emptying toilets. Another option is breaking the law and emptying them on sidings prejudice to the existing provisions on environmental protection.

And everything by a complete lack of global vision and strategies for ensuring appropriate location and accessibility points wherever this is justified by the operational needs of the railways. These points should arise at least in the neighborhood of major passenger hubs and provincial cities, and at the ends of lines having the character of a typical tourist and seasonal, both in the mountains and the sea.

The presence of such infrastructure among others would encourage operators to run more seasonal trains, tourist, which apart from profits from the provision of disposal of feaces services and launching, would result in additional manager revenue for the sale of routes for trains, and the economy of our country could count on a reduction of external costs. About the fact that this problem is serious indicates recent reports by media about problems with overfilled toilets in trains EC Premium. This smelly problem can be easily solved if e.g. in Krakow, Gdansk and Gdynia were generally holding tracks equipped with professional devices for disposal of feaces with the use of vacuum pumps, for emptying a 200 liter tank faeces in 2-3 minutes instead of $10-15$ as it is place at the traditional slurry pumps. 


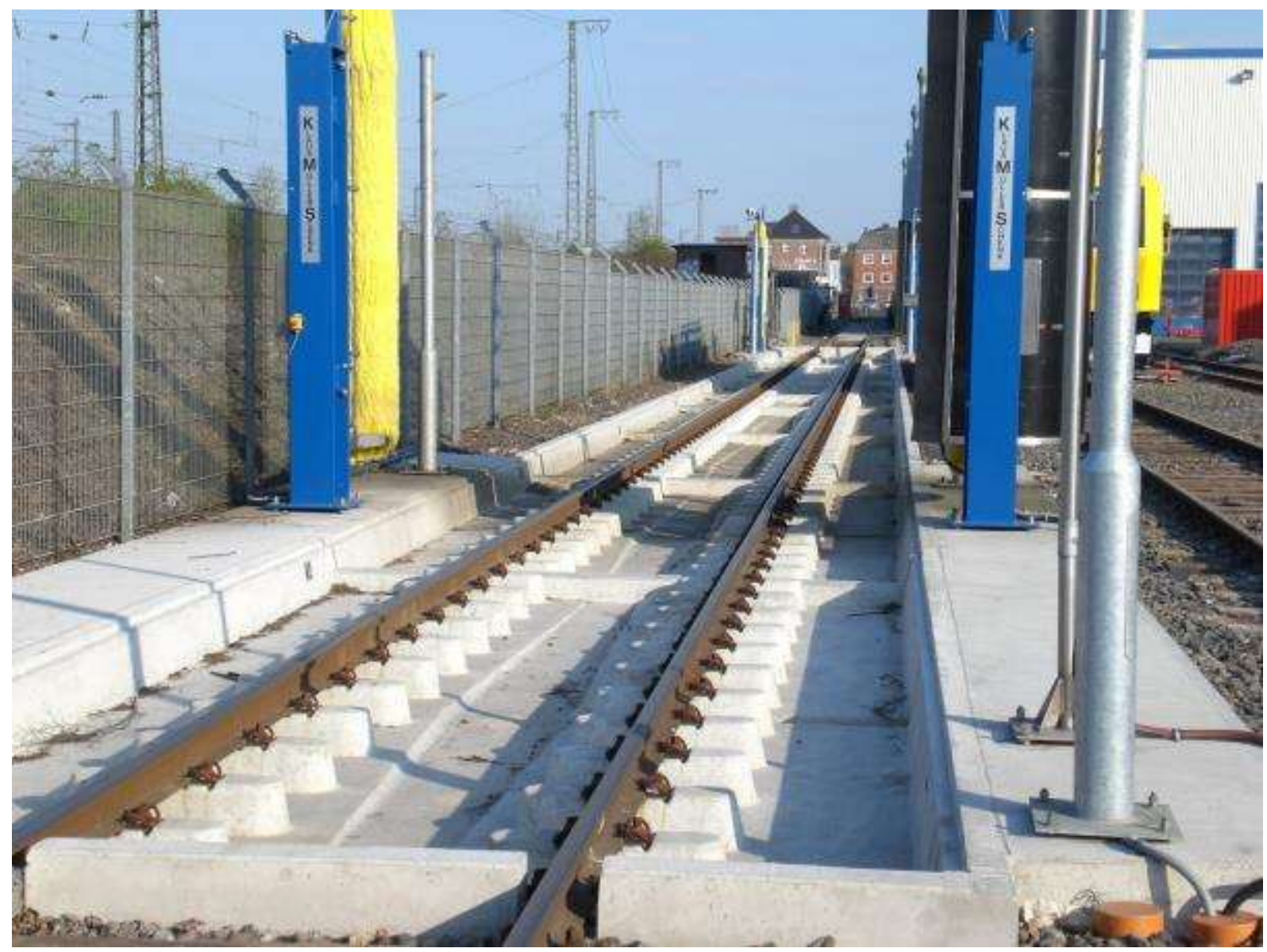

2. Ecological point of vehicle washing stations, made on sealed track tubs GTW system (Pic. BFL Lauchhammer)

\section{Points of washing and external cleaning}

Similar problems concern the points of rolling stock washing and cleaning. While the construction of modern and professional points of rolling stock maintenance by operators equipped with closed washing is essential and is on their side, it would be irrational to their placement at each station where trains are accommodated. It is irrational that empty trains drive down to the parent point of maintaining only to make a cursory cleaning or simple external cleaning windows, railings, etc. such operations rational operators perform at the endpoints, which are usually disposed on the ends of routes. This is the effect of the economic strategy that trains in the morning bring passengers to city centers and in the evening they take them back, spending the night at the endpoints. The parking time is usually used just for washing and cleaning. However, today these activities are carried out in degrading any standard of safety, with environmental protection without ability to meet the requirements of ever increasing rigor of keeping modern vehicles clean. Apart from the fact that there is no official list of the available points on the network of PKP PLK in which you can make external washing of vehicles, conducted in 2013-2014 studies have shown that most of the places where the cleaning process is carried out, has no authorization for placing substances harmful to the environment including the groundwater. Potential announced inspections of the State Sanitary Inspection end with a "temporary" dry-cleaning, which is in clear contradiction to the requirements of the tenders. The specificity of closed areas which is the railway area and some kind of conspiracy of silence that occurs between the infrastructure manager, operator and the company carrying out cleaning services of rolling stock causes that in Poland there is a huge gray area in this regard. With impunity and with full premeditation we pollute the environment with very harmful substances coming from the external cleaning of rail 
vehicles without making any effort to change the status quo. Perhaps this is due to ignorance, ignorance of the law or belief that anyway we manage to avoid any liability, because no one controls the railway areas. Unfortunately, criminal liability for environmental pollution is very strict and in addition inevitable. Article 7 of the Environmental Protection Act of 27 April 2001 clearly says that "whoever causes pollution, bear the costs of removing the effects of this pollution."

More detailed regulations on the use of water resources determines the Water Law of 18 July 2001, which defines the art. 41, paragraph 1, that "bringing wastewater into waters or into the ground in the ordinary or special use of water should be cleaned to the extent required by law (...)". Similar requirements brings art. 42. paragraph 1 of the above Act, which says that "placing sewage into the water or the ground are obliged to ensure the protection of waters from pollution, in particular through the construction and operation of facilities for the protection and, where appropriate, reuse of treated wastewater. The choice of place and method of use or disposal of sewage should minimize the negative impact on the environment. " According to the art. 194 of this Act, "who (...) does not ensure the protection of water against pollution in accordance with the requirements referred to in Article. 42 subject to a fine".

Therefore, the gross negligence is skipping the process of modernization of the stations or entire investment nodes in the points of keeping cleanliness according to the required environmental regulations. Such activities should be carried out in the interest of the infrastructure manager, and representatives of local governments responsible for issuing water permits and environmental protection. It is enough that within the project will be planned the construction of holding tracks on the length and amount consistent with the needs of the freight consulted with experts and the transport organizer, along with intending one of them for the purposes of a vehicles external washing point. As part of the construction of these tracks you can easily equipped the surface of one of them with a rail collecting troughs for the length of one of the vehicle (usually from 60-120 meters), with the construction in the vicinity of the tank and the liquid waste. This installation should be equipped with both sides paved pedestrian and good lighting to ensure personnel adequate safety. 


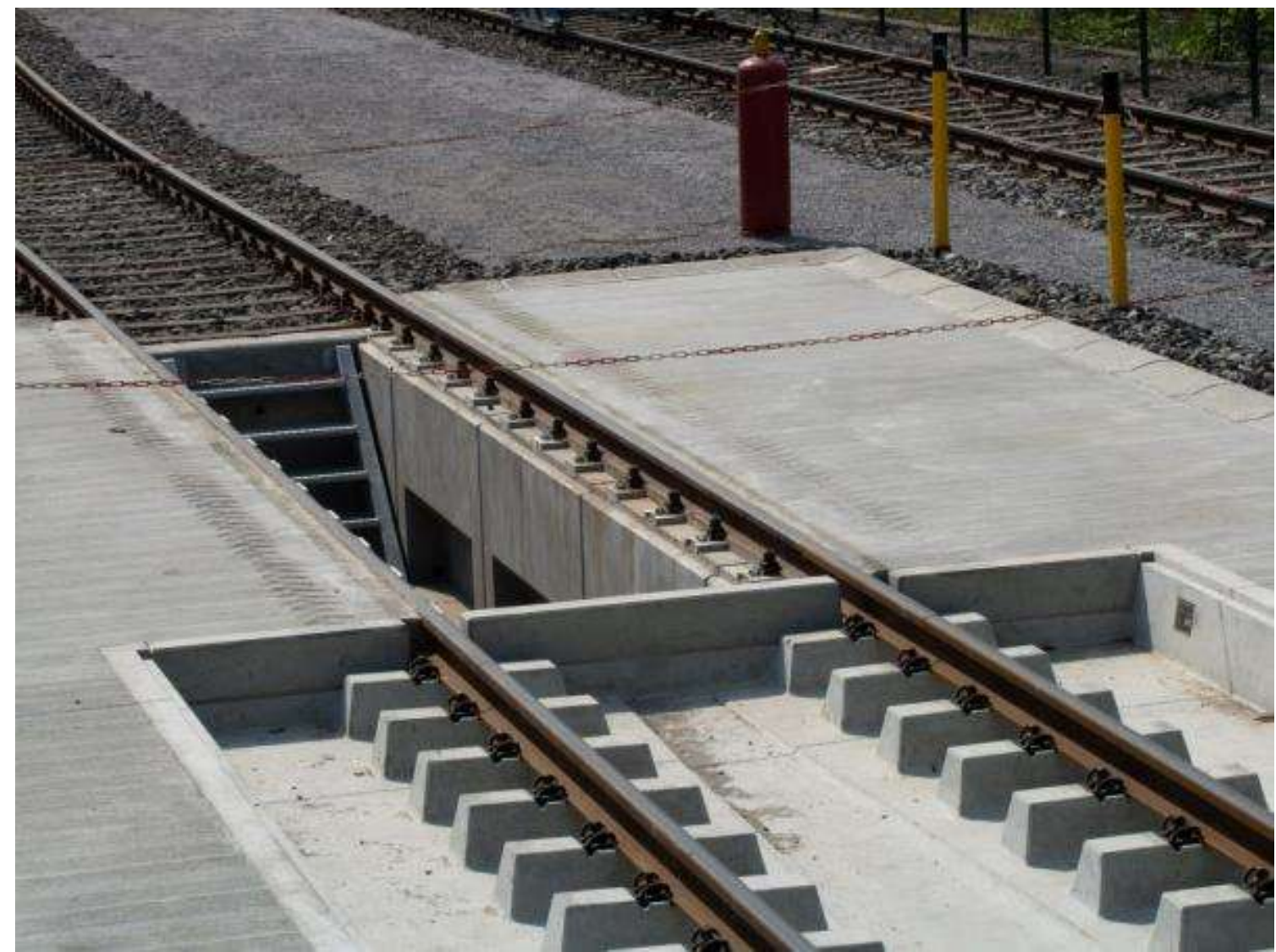

3. An example of the point of rolling stock maintenance - channel inspection of AG system and bath-track GTW system (Pic. BFL Lauchhammer)

\section{Internal cleaning points}

One of the basic elements of transport preferences, determining the choice of rail as a mean of transport is the cleanliness at the level acceptable by the customer. Modern rolling stock, gradually displacing age vehicles requires a completely different technology than cleaning methods used so far for the railway. The use of modern fabrics for the upholstery of seats, which, unlike plastic or dermis, requires professional and daily vacuuming instead of wiping with a damp cloth. Similarly for cleaning floors should be used mechanical scrubber instead of the usual rags soaked in dirty water and wrapped on wooden broomsticks, causing smearing dirt instead of its removal. Similarly, washing windows, headrests, tables, walls, shelves and the rest of gallantry use of individual chemicals-based nanotechnology tailored to the individual requirements of the material they are made of. This necessitates the use of specialized cleaning trolleys similar to those used in supermarkets or hospitals. Besides collected on the train waste should be segregated and stored in accordance with the requirements of the Waste Act of December 14, 2012.

All of these requirements make the points for seemingly trivial internal cleaning of rail vehicles should be suitably located and equipped so as to meet the security requirements both with regard to the railway system, environmental protection and safety of mobile workers cleaning. For this reason, they must have a secure accesses, be protected from active railroad tracks, be properly lit, have access to clean running water and decanting plants, which today are commonly poured over the tracks. The use of mechanical cleaning (vacuum cleaners, scrubber) require a constant power supply, which should be supplied from external power points located adjacent to the track designed to maintain the cleanliness. Each of these tracks should be equipped with platforms allowing free entry to the vehicle, including the possibility of a heavy mechanical equipment and night cleaning. The amount of such a zone should be 
$0.76 \mathrm{~m}$ above the rail, and therefore have a height typical for the platform and the surface to protect against slipping and, if possible have handrails.

Contrary to appearances, these investments should be carried out by the infrastructure manager and the bailout e.g. from environmental protection fund, because their lack makes it impossible to build an interoperable rail network and causes railway areas pollution.

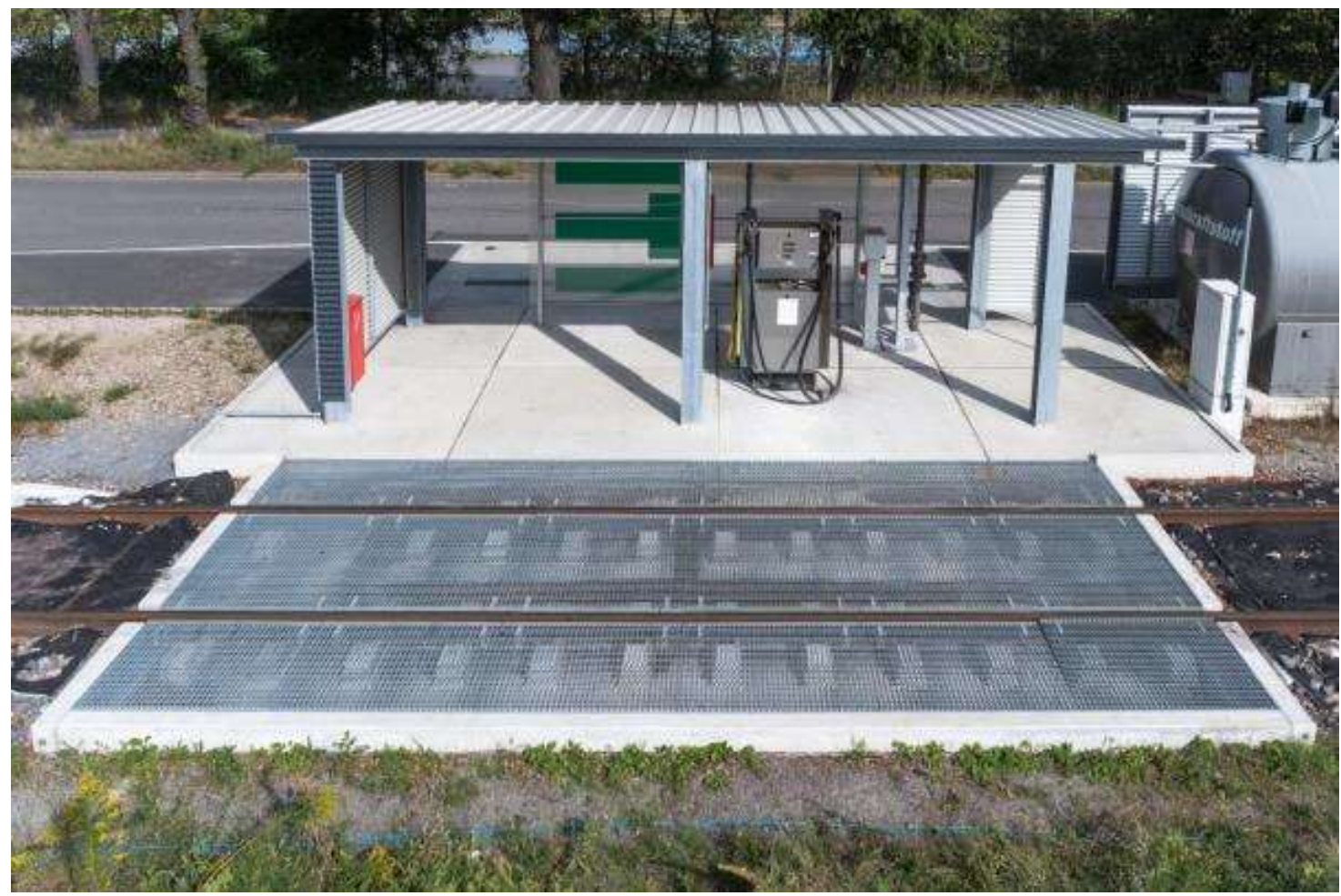

4. Eco-friendly fuel station for refueling locomotives, made of non-ballasted reinforced concrete precast system GTW

\section{Inspection and repair points}

By the construction of holding tracks should be as far as possible created widely available points for inspection and repair, equipped with inspection channels and platforms for checking slides pantographs. Construction of these points will improve both the efficiency of rolling stock which is at the disposal of operators and eliminating unnecessary passes in order to perform maintenance and inspections related to the first level of maintenance (P1). It will also more quickly and accurately diagnose any irregularities that may occur the work vehicles used in the transport of goods, thereby raising the overall level of safety of the railway system.

Construction of inspection and repair points consisting with canals and inspection bridges should be carried out at stations and junctions where in winter and summer seasons trains begin and end their courses. Similar facilities should be also built at every station yard, the port and a large generating freight node. Of course, in the case of points dedicated for passenger length of such channels should be at least equal to half the length of fourelemented vehicle, while maintaining a secure entrance to the canal on both sides of the track channel and the appropriate length of the track before and after the channel enabling a review of the chassis as much as four-elemented vehicles. The optimal solution, especially in the metropolitan area would be to build channels with a length of 80-90 meters, and in the case of points for locomotives with a length of approx. 25-30 meters.

These points should have easy access for delivery vans, adequate lighting, and connection to the technical equipment power supply with adequate power and voltage. 


\section{Points of rolling stock irrigation}

While in the framework of washing and cleaning points or inspection channels will not be performed the installation of irrigation, such arrangements should be made for the other holding tracks or station (e.g. endpoints). Such connections must be located along the track to a minimum length of $100 \mathrm{~m}$ distance of about 20-25 m apart, allowing simultaneous launch both the storage units and the wagon compositions, using connections with a maximum length of 5-10 meters. Installation and connection to the system must be protected from freezing and frost, so that it is possible to use them all year round. Only then it makes sense to invest in new rolling stock and closed toilets system.

\section{Tracks for the transport of dangerous goods}

The vast majority of discussed above elements of the infrastructure services concerned construction of facilities for the needs of interoperability and ecology passenger. However, the main intentions of building a system of interpretation of European railways is to create a transport system that allows the carriage of cargo including dangerous goods. For this reason, it is worth recalling that nearly for 3 years there are regulations which, although they are not derived from the law on rail transport, have a significant impact on any investment and the whole railway system in the coming years. This is the Regulation of the Minister of Transport, Construction and Maritime Economy of 25 April 2012 on technical conditions for tracks to the emergency withdrawal of damaged railway wagons carrying dangerous goods issued on the basis pursuant to art. 106 paragraph. 1 point 2 of the Act of 19 August 2011 on the transport of dangerous goods.

In accordance with these provisions the entire railway infrastructure until 31 December 2020, should be equipped with tracks for emergency withdrawal of damaged railway wagons carrying dangerous goods. Although the regulation does not specify exactly on which stations such tracks should be built, however, they indicate that such places will be built on the existing border, timing and maneuvering stations on which take place taking, maneuvering, humping or compilation of trains carrying dangerous goods. It is worth mentioning that the legislator does not specify the types of hazardous materials on which this provision applies. This is very important from the point of view of changes which have entered into RID in 2014 for classifying coal, coke and anthracite as dangerous in class 4.2. Thus, the number of stations that require these installations is almost obligatory for each station and a railway siding on which are performed maneuvers or shaping compositions from coal, coke or anthracite.

Each of the tracks for emergency withdrawal of damaged railway wagons carrying dangerous goods should meet the following criteria:

- have a minimum of $60 \mathrm{~m}$ usable length and meet the required parameters of the railway track,

- have insulation to protect against stray currents in accordance with the requirements of the Polish Standards concerning safety insulation against stray currents caused by electric traction DC,

- may not be under traction network,

In and of itself position for an emergency withdrawal of damaged railway wagons carrying dangerous goods should :

- be at least $35 \mathrm{~m}$ in length,

- be located at a distance of not less than:

- $50 \mathrm{~m}$ from public buildings and residential buildings,

○ $30 \mathrm{~m}$ from buildings other than those specified above, 
- $25 \mathrm{~m}$ from the axis of main fundamental track or plain line,

○ $15 \mathrm{~m}$ from the axis of the nearest track with traction network,

$\circ 10 \mathrm{~m}$ from ditches, manholes and drainage facilities,

- be equipped with a lightning and grounding protection system in accordance with the requirements of the Polish Standards defining the requirements for the installation of lightning and grounding protection,

- have installed a weather vane,

- be marked with an array indicating the location of the stand and signs informing about the threat,

- a fire and the location of hydrant compatible with European Union standards on safety signs,

- have an open hydrant with a capacity of at least $10 \mathrm{dm} 3$ / s,

- have a sealed surface to protect it from dangerous goods into the soil, surface water and groundwater,

- be located outside the recess area,

- have an access to a hardened access allowing passage or returning the vehicle,

- be equipped with a geomembrane rain cape not smaller than $6 \times 4 \mathrm{~m}$, with links provided with eyed holes for hanging under the carriage, with space to escrow at the technical station that supports the rack.

The basic element of the safety lane surface penetration into the soil hazardous materials should be integrated slab track surface, made of reinforced concrete elements providing, as in the case of rolling stock cleaning points, sewage potential hazardous materials to an external tank with a capacity of $20-40 \mathrm{~m} 3$.

Both the tank and rail-paved surface, should have the strength of concrete in the class minimum C35 / 45 PN-EN206-1 and fulfill class resistance to exposure to the minimum: $\mathrm{XC} 4, \mathrm{XF} 4, \mathrm{XD} 3, \mathrm{XM} 2$.

\section{Traction network power supply}

The gradual process of modernization of the rolling stock park also for its interoperability will make that on railway lines there will be becoming increasingly frequent modern universal locomotives with a capacity of 5-6 MW. Vehicles of this type because of its traction allow to be both heavy freight trains and passenger trains juxtaposed with cars one and two-level reaching the appropriate combination acceleration comparable to a modern electric trainsets. Such a situation forces the design of the entire system power supply so as to rise to even some type of locomotives in one substation does not cause a voltage drop and there was no reason for limiting the capacities upgraded lines.

Possibility of driving trains with one locomotive through many countries will cause emergence of a transport relationship carried by two active high-power locomotives. It is therefore expected that, especially on the lines connecting the seaports with the south of our country, and running through the corridors of European mountain sections of border crossings, as well as the outlets with large cities and industrial districts, freight trains will be run by two locomotives with a total capacity to $12 \mathrm{MW}$.

It may refer, in particular, to heavy container trains, which, in order to meet the competition of the road will be routed to its full length and maximum design parameters platforms $(120 \mathrm{~km} / \mathrm{h})$, as soon as possible in order to connect terminals. Moreover, most likely the only chance to increase the capacity of railway lines in the area where the exhausted capacities, e.g. in the Tricity region will be a requirement to increase speed trains just by increasing the power of locomotives. Actions in this direction will be certainly cheaper than building additional tracks. For this reason, in the framework of modernization of main railway 
lines must be strictly design the rail network and the entire power supply systems with a maximum current consumption of the order of 11-12 MW from a single composition. This will allow for a smooth introduction of new rolling stock within the next 20-30 years without re-modernization of existing power systems in line with the growing needs of carriers.

\section{Summary}

Further skipping the process of modernization needs of the rail operators will lead to a lack of full use of the benefits of multi-million dollar investment to improve the rail infrastructure at a loss for interoperability. It can also threaten incurring additional costs by the infrastructure manager and carriers due to disregard their needs and legal requirements, especially in the field of environmental protection and water resources. Detailed guidelines and scope of the framework guidelines for the unification of these objects should be subject to a wider discussion among the representatives of the railway environment with particular emphasis on experts, engineers, infrastructure managers of railway passenger and freight and public transport operators. 